\title{
Post-bulbar and coexisting ulceration: unique features of peptic ulcer in Hyderabad
}

\author{
S S C Rao, K V R Murthy
}

\begin{abstract}
Post-bulbar ulceration is uncommon, but a pilot study in Hyderabad showed a high incidence. We therefore carried out a prospective endoscopic study of the distribution of peptic ulceration and its relation to symptoms and demography. Of the 360 consecutive patients referred for endoscopy, 113 (92 men, 21 women) had peptic ulceration. Median age 35 years, median duration one year. Five patients (4\%) had gastric ulcer, $77(68 \%)$ had duodenal ulcer, and $31(28 \%)$ had coexisting gastric and duodenal ulcer. The duodenal ulcer was found in the pyloric canal in $14 \%$ of patients, in the bulb in $80 \%$, and the post-bulbar region in $56 \%$ of patients. Sixty seven per cent of duodenal ulcers were located at more than one site. The incidence of post-bulbar $v$ bulbar ulcer was 1:1.5. Deformed bulb was seen in $50 \%$ of duodenal ulcer patients, but haemorrhage and stenosis were uncommon. Except for nocturnal pain, there were no differences in symptoms between the groups. Forty two per cent of patients smoked, $15 \%$ chewed tobacco, and $18 \%$ drank alcohol; almost all were men. Sixty four per cent drank tea. The staple diet $(85 \%)$ was rice, and $70 \%$ used tamarind and spices daily. Duodenal ulcer was three times more common than gastric ulcer with a high incidence of post-bulbar and coexisting ulcer. It affected a younger and predominantly male population, and was not associated with a higher rate of complication.

(Gut 1993; 34: 1327-1330)
\end{abstract}

Post-bulbar ulceration is reported to be uncommon, but it is associated with a higher incidence of complications, such as bleeding, perforation, and stenosis. ${ }^{1-6}$ During routine endoscopy, we found a high incidence of ulceration in this province, and a pilot study showed that $14 / 30$ patients had ulceration in the second part of the duodenum. This has not been seen before, although a higher prevalence of duodenal ulceration has been described in south India. ${ }^{7-11}$ In most of these studies, the diagnosis of peptic ulcer was based on symptoms and single contrast barium studies. Hence, it is possible that post-bulbar ulceration may have been missed. The reasons for the high incidence are not known, ${ }^{12}$ but environmental factors and diet have been suggested. ${ }^{89}{ }^{13-15}$

We undertook a prospective endoscopic study to record the site, size, and distribution of peptic ulceration and to relate these findings with symptom patterns and demographic features.

Patients and methods

Between July 1989 and April 1990, 360 patients were referred to our department for endoscopy. These were inpatients and outpatients from a charitable teaching institute (DDH) and a private hospital (PNH). A lignocaine solution was used to spray the pharynx and they then had an oesophagogastroduodenoscopy using an Olympus gastroscope (OES, GIF, Q10), with minimal or no sedation. Patients with a clear breach of mucosa (ulcer or erosion) in the stomach or duodenum, or both were included in the study. This consisted of 119 patients, six of whom were excluded because they were found to have a carcinoma in the lesser curve (1), greater curve (1), antrum (2), antroduodenum (2). Thus, data from 113 patients were included in the study. The endoscopy was normal in 104 patients. The remaining 137 patients were found to have other abnormalities including a hiatus hernia, oesophageal problems, gastritis, and duodenitis, and these were excluded from the study.

The endoscopy was performed by a single observer (SSCR). The lesions in the stomach or duodenum were classified as ulcers or erosions and their number, size, and location were recorded. The site of ulceration was categorised as those occurring on the lesser curve, greater curve, fundus, antrum, pyloric canal, bulb (anterior, posterior or inferior wall), and the postbulbar region. Associated features, if any, such as stigmata of recent haemorrhage, stenosis, deformity of bulb, previous surgery, and stomas were noted.

After the operation, patients with peptic ulceration were interviewed by an independent observer (KVRM), who was unaware of the endoscopy findings. Using a standard questionnaire, the following information was collected; age, sex, occupation, rural/urban dwelling, history of smoking, alcohol consumption, tea and coffee consumption, and tobacco chewing. In this province, tobacco is commonly chewed as 'zarda pan.' This consists of tobacco paste and powder, which is flavoured and wrapped inside a beetle leaf. In addition a history of non-steroidal anti-inflammatory drugs (NSAID) and other drugs, family history, characteristics of the pain and its relation to food, and other associated

TABLE I Prevalence of peptic ulceration in relation to occupation

\begin{tabular}{lrllll}
\hline Occupation & No & $(\%)$ & $\begin{array}{l}\text { Gastric } \\
\text { ulcer }\end{array}$ & $\begin{array}{l}\text { Coexisting } \\
\text { ulcer }\end{array}$ & $\begin{array}{l}\text { Duodenal } \\
\text { ulcer }\end{array}$ \\
\hline $\begin{array}{l}\text { Professional } \\
\text { Agriculture }\end{array}$ & 21 & $(19)$ & 1 & 5 & 15 \\
$\quad$ worker & & $(17)$ & 2 & 9 & 8 \\
$\begin{array}{l}\text { Housewife } \\
\text { Skilled }\end{array}$ & 18 & $(16)$ & 1 & 3 & 14 \\
Business & 16 & $(14)$ & 0 & 4 & 12 \\
Unskilled & 15 & $(14)$ & 0 & 4 & 12 \\
Others & 8 & $(7)$ & 1 & 4 & 10 \\
Total & 113 & & 5 & 31 & 6 \\
\end{tabular}


TABLE II Anatomical distribution of gastric and duodenal ulcer. The Table shows the number of patients with ulceration at each site

\begin{tabular}{|c|c|c|c|c|c|c|c|c|}
\hline & \multicolumn{4}{|l|}{ Stomach } & \multicolumn{4}{|c|}{ Duodenum } \\
\hline & Fundus & $\begin{array}{l}\text { Greater } \\
\text { curve }\end{array}$ & $\begin{array}{l}\text { Lesser } \\
\text { curve }\end{array}$ & Antrum & $\begin{array}{l}\text { Pyloric } \\
\text { canal }\end{array}$ & Bulb & $\begin{array}{l}\text { Post- } \\
\text { bulbar }\end{array}$ & $\begin{array}{l}\text { Bulb and } \\
\text { post-bulbar }\end{array}$ \\
\hline $\begin{array}{l}\text { Gastric ulcer } \\
(5 / 113)\end{array}$ & 1 & 3 & 3 & 2 & - & - & - & - \\
\hline $\begin{array}{l}\text { Coexisting ulcer } \\
(31 / 113)\end{array}$ & 1 & 2 & 8 & 25 & 12 & 17 & 8 & 11 \\
\hline \multirow{2}{*}{$\begin{array}{l}\text { Duodenal ulcer } \\
\quad(77 / 113)\end{array}$} & - & - & - & - & 3 & 31 & 10 & 31 \\
\hline & 2 & 5 & 11 & 27 & 15 & 48 & 18 & 42 \\
\hline
\end{tabular}

Note: $67 \%$ of duodenal ulcer and $28 \%$ of gastric ulcer patients had ulcers at more than one site, and patients have been counted more than once.

TABLE III Endoscopic features of gastric, bulbar, and postbulbar ulcers

\begin{tabular}{lcccl}
\hline & $\begin{array}{l}\text { Gastric } \\
\text { ulcer }\end{array}$ & $\begin{array}{l}\text { Bulbar } \\
\text { ulcer }\end{array}$ & $\begin{array}{l}\text { Post- } \\
\text { bulbar }\end{array}$ & $p$ \\
\hline No & 36 & 90 & 60 & - \\
Erosions & $51 \%$ & $37 \%$ & $34 \%$ & NS \\
Ulcer $<1 \mathrm{~cm}$ & $41 \%$ & $39 \%$ & $33 \%$ & NS \\
Ulcer $1-2 \mathrm{~cm}$ & $5 \%$ & $21 \%$ & $27 \%$ & $<0 \cdot 05$ \\
Ulcer $>2 \mathrm{~cm}$ & 0 & $3 \%$ & $6 \%$ & $<0 \cdot 05$ \\
Ulcer(s) at single site & $72 \%$ & $33 \%$ & $40 \%$ & $<0 \cdot 05$ \\
Ulcer(s) at multiple sites & $28 \%$ & $67 \%$ & $60 \%$ & $<0 \cdot 05$ \\
Bleeding (SRH) & $5 \%$ & $4 \%$ & $3 \cdot 3 \%$ & NS \\
Stenosis & 0 & $4 \%$ & $7 \%$ & $<0 \cdot 05$ \\
Deformity & 0 & $50 \%$ & $30 \%$ & $<0 \cdot 001$ \\
\hline
\end{tabular}

$\mathrm{p}=$ significantly different from gastric ulcer; no differences were seen between bulbar and post bulbar ulcer. No=total number of patients with ulceration at each site. Some patients are included in more than one group but the ulcers have been counted only once. SRH = stigmata of recent haemorrhage.

gastrointestinal symptoms (experienced at least twice a week) were noted. A detailed dietary history with particular reference to the consumption of rice, wheat, lentils, chillies, and tamarind was also obtained. Tamarind (botanical name $=$ tamarindus indica) beans are dried or roasted, or both and are used to make a soup which is popularly called mulagatawny soup or rasam. Traditionally it is believed that the soup has digestive and carminative effects. The soup is acidic and $0.5 \mathrm{ml}$ is capable of neutralising 0.05 $\mathrm{ml}$ of $\mathrm{N} / 10 \mathrm{NaOH} .^{16}$

Statistics - the patients were divided into three groups, based upon the site of ulceration, into those with gastric ulcer, coexisting gastric and duodenal ulcer, and duodenal ulcer. Because the data were non-parametric, statistical differences between the groups were calculated using Wilcoxon's rank sums tests.

\section{Results}

\section{PATIENT CHARACTERISTICS}

The study group consisted of 113 consecutive patients with peptic ulceration, of whom 92 were

TABLE IV Relation between habits and prevalence of peptic ulceration

\begin{tabular}{llllll}
\hline & $\begin{array}{l}\text { No of } \\
\text { patients }\end{array}$ & $M / F$ & $\begin{array}{l}\text { Gastric } \\
\text { ulcer } \\
(n=5)\end{array}$ & $\begin{array}{l}\text { Coexisting } \\
\text { ulcer } \\
(n=31)\end{array}$ & $\begin{array}{l}\text { Duodenal } \\
\text { ulcer } \\
(\boldsymbol{n}=77)\end{array}$ \\
\hline Beverage & 73 & $62 / 11$ & 1 & 23 & 49 \\
Tea & 15 & $11 / 4$ & 2 & 5 & 8 \\
Coffee & 15 & $12 / 3$ & 1 & 3 & 11 \\
Tea and coffee & 10 & $7 / 3$ & 1 & 0 & 9 \\
Abstainers & 47 & $47 / 0$ & 0 & 14 & 33 \\
Smoking & 16 & $15 / 1$ & 1 & 4 & 11 \\
Tobacco chewing & 42 & $42 / 0$ & 1 & 12 & 29 \\
Alcohol & & & & &
\end{tabular}

men and 21 were women (ratio was $4 \cdot 4: 1$ ). The median age was 35 years (range $14-79$ years). The median duration of symptoms was one year (range 14 days-20 years). The age distribution and the length of history were similar between the three groups, but male/female prevalence was 4/1 (gastric ulcer), 28/3 (coexisting gastric and duodenal ulcer), 60/17 (duodenal ulcer). Fifty four patients $(48 \%)$ were living in rural communities, $49(44 \%)$ were living in the city, and 10 patients $(8 \%)$ had migrated to the city within the last two years. Twenty one patients $(19 \%)$ had a family history of peptic ulceration. Eleven $(10 \%)$ patients were taking NSAIDs. Table I shows the prevalence of ulceration in relation to occupation, which also displays the heterogenous nature of the study population.

\section{DISTRIBUTION OF ULCERATION}

Gastric ulcer - 36 patients (32\%) had a gastric ulcer. Five ( $4 \cdot 1 \%)$ patients had ulcers confined to the stomach and $31(28 \%)$ had coexisting ulceration. Table II shows the distribution of gastric ulcer, and summarises the other features noted.

Duodenal ulcer - 108 (95\%) patients had a duodenal ulcer, of whom $77(68 \%)$ had ulceration confined to the duodenum. Duodenal ulcer:gastric ulcer ratio was 3:1. Table II shows the distribution of ulceration. In 48 patients (44\%) the duodenal ulcer was confined to the bulb, in 18 patients $(17 \%)$ the post-bulbar area, and in 42 patients (39\%) the ulcers were seen in both the regions. Thus $60 / 108$ patients $(56 \%)$ had post-bulbar ulceration. In 15 patients $(14 \%)$ the duodenal ulcer was located in the pyloric canal, in 77 patients $(71 \%)$ the anterior wall, in 45 patients $(41 \%)$ the posterior wall, and in 34 patients $(31 \%)$ in the inferior wall. Table III shows the endoscopic features and their differences from gastric ulcer. Stigmata of recent haemorrhage and stenosis was seen in three patients each with bulbar ulcers and in two and four patients with post-bulbar ulcers.

\section{DEMOGRAPHIC FEATURES}

The staple diet was rice in 97 patients $(85 \%)$, and the remainder ate a mixed diet of rice, wheat, and other cereals. Seventy nine patients $(70 \%)$ used tamarind daily, either in the form of a soup or a pickle. There was no correlation between beverage consumption and site of ulceration (Table IV). Almost all of the patients addicted to smoking, chewing tobacco, and alcohol were men (Table IV).

SYMPTOM PATTERNS

The proportion of patients reporting a symptom in each group was remarkably similar and except for nocturnal pain, there was no significant difference between the three groups. Hence the pooled data are presented. The most common site of pain was the epigastrium (63\%), then the right hypochondrium (27\%), the umbilical area $(26 \%)$, the right lower quadrant $(14 \%)$, and the left hypochondrium $(8 \%)$. Forty per cent experienced pain at more than one site and $6 \%$ were painless. The pain was aggravated by food in 
$50 \%$ of patients, food containing chillies in $44 \%$, fried and fatty food in $25 \%$, stress in $21 \%$, and hunger in $11 \%$. The pain was relieved by food in $25 \%$ of patients, and by antacids in $11 \%$, but in $57 \%$ there was no relieving factor. The pain was burning (43\%), stabbing (25\%), dull ache $(20 \%)$, colicky (11\%), and gripping (8\%), and radiated to the back in $20 \%$ of patients. Only $10 / 45$ patients with a posterior wall ulcer had symptoms radiating to the back, showing a poor correlation between site of ulcer and radiation of pain. Nocturnal pain was reported by $72 \%$ of patients with duodenal ulcer, $20 \%$ of patients with gastric ulcer, and $52 \%$ of patients with coexisting ulceration, and there was a significant difference between patients with duodenal ulcer and gastric ulcer $(\mathrm{p}<0.02)$.

\section{ASSOCIATED FEATURES}

The following additional symptoms were reported (parenthesis represents proportion of patients); nausea (42\%), vomiting $(27 \%)$, heartburn $(50 \%)$, excessive burping (38\%), hiccups ( $24 \%)$, flatulence $(29 \%)$, constipation $(27 \%)$, and diarrhoea $(5 \%)$.

\section{Discussion}

Since the advent of fibreoptic endoscopy, there have been limited studies on the distribution of peptic ulceration ${ }^{17-20}$; post-bulbar ulceration is rarely mentioned. In a meticulous study of 200 duodenoscopies in the United Kingdom, postbulbar ulceration was not seen. ${ }^{17}$ Our prospective study shows that $56 \%$ of patients in this province had post-bulbar ulceration, and $17 \%$ had ulceration exclusively in this segment. This contrasts with the reported incidence of less than $5 \%$ from data derived from postmortem studies and retrospective radiological analysis. ${ }^{2-6}$ These studies may not reflect the true incidence, because stress ulceration may occur before death, and may be an incidental finding at necropsy, ${ }^{2}$ and radiography under optimal conditions has a sensitivity of $54 \%$ for detecting gastroduodenal lesions. ${ }^{18}$ Clinical experience in the West, however, also suggests that post-bulbar ulceration is uncommon. ${ }^{1}$ Thus, our findings represent, either a unique feature or a changing pattern of duodenal ulceration, in this geographical area. Our study did not include a control group from the same population, none the less, we saw certain demographic features, which may contribute to the high incidence and more extensive ulcer disease. Unlike the West, where coffee is preferred, ${ }^{21}$ two thirds of patients drank moderately excessive amounts of tea. Tea is a potent stimulant of acid secretion. ${ }^{22}$ The staple diet was rice $(85 \%)$, which was usually consumed twice a day, mixed with spiced lentils, tamarind soup, and a peppered pickle. A higher incidence of duodenal ulcer and a sixfold greater relapse rate has been reported among rice eaters compared with wheat eaters. ${ }^{151623}$ In addition, spices and peppers are acidic, stimulate gastric secretion, ${ }^{16} 24-26$ and cause reddening and desquamation of mucosa. ${ }^{2428}$ Although, the role of diet and spices in the pathogenesis of peptic ulceration is controversial, ${ }^{1329}$ our findings suggest that these factors may play a part by hindering the healing process. Another important factor could be the high prevalence of infection with Helicobacter pylori. ${ }^{30}$ A recent study has reported that $80 \%$ of the patient population in Hyderabad has IgG specific antibodies against $H$ pylori, with a high occurrence at a younger age, compared with only 20 $30 \%$ in the West. ${ }^{30}$

The incidence of duodenal ulceration was three times higher than gastric ulceration. The bulbar lesions were commonly seen on the anterior wall, as seen previously, ${ }^{\prime}$ and $50 \%$ of patients had a deformed bulb suggesting chronicity. Two thirds of duodenal ulcers were multiple, and were situated at more than one site, whereas more than two thirds of gastric ulcers were solitary. Interestingly, $27 \%$ of patients had coexisting gastric and duodenal ulceration. This incidence was also higher than the 3-12\% figure quoted in published works, ${ }^{3132}$ and was not associated with a higher incidence of complication. The pattern of gastric ulceration was also unique, as $65 \%$ were situated in the antrum and $86 \%$ were associated with duodenal ulceration, by contrast with a previous radiological report of $43 \%$ and $42 \%$ respectively. ${ }^{33}$ Thus, peptic ulceration in south India is predominantly a disease affecting the antrum, bulb, and post-bulbar region - that is, areas exposed to the ravages of acid and pepsin.

The symptom patterns did not show any differences from those reported from the West, ${ }^{2034-36}$ and also between the three ulcer groups, confirming recent views ${ }^{37}$ that except for nocturnal pain, dyspeptic symptoms alone cannot differentiate gastric and duodenal ulceration. Patients with post-bulbar ulceration also exhibited similar symptoms. Peptic ulcer was five times more common in men than women, and this sex difference may be because of the lower incidence of smoking, alcohol, and tobacco consumption among women, although among male patients the prevalence of these habits was similar to the West. ${ }^{20}$

In our series, bleeding was encountered in only two patients, and stenosis in four patients with post-bulbar ulceration, whereas previous studies have reported a higher rate of complication. ${ }^{46}$ One explanation for this discrepancy could be a bias in patient selection. In our study, this was unlikely, because we performed a prospective evaluation of patients derived from all cross sections of society (Table I). In contrast, previous studies have reported retrospective data from patients in hospital. Moreover, barium studies can miss erosions and post-bulbar ulcers. ${ }^{517}$ Both factors may have overestimated the complication rate. The lower incidence of bleeding was not surprising, as this problem is rare in India for reasons not yet understood ${ }^{12}$; a lower incidence of NSAID consumption $(<10 \%)$, and a comparatively younger and predominantly male population with ulcer disease may be important in preventing this complication.

Our study shows an unusually high incidence of chronic post-bulbar and coexisting peptic ulceration in a younger and predominantly male population, which is associated with a lower rate of complication. Clearly, these findings merit a 
further study to confirm and elucidate the pathophysiological mechanisms and causes of ulceration.

This work was carried out at Durgabai Deshkmukh Hospital and Pramila Nursing Home, Hyderabad, India. We wish to thank Dr S R Rao and physicians from both institutions for their support. We are also grateful to Dr K D Bardhan, for his expert comments during the preparation of this manuscript and to Ms Sandy Plank during the preparation of this manuscript and to Ms Sandy Plank for her superb assistance with typing. Portions of this work have 9: A7 and in Gastroenterology 1991; 100: A15.

1 Bardhan KD. Special categories of duodenal ulcer. In Bardhan KD, ed. Perspectives in duodenal ulcer. 2nd ed. Welwyn Garden City: Smith Kline \& French Laboratories Limited, 1981: 39-42.

2 Portis SA, Jaffe RH. A study of peptic ulcer based on necropsy records. ЭAMA 1938; 110: 6-13.

3 Sturtevant M, Shapiro LL. Gastric and duodenal ulcer: frequency, number, size, shape, location, color, sex and age in seven thousand seven hundred necropsy records at Bellevue Hospital, New York. Arch Intern Med 1926; 38: 41-56.

4 Alvarez LF, Farinas PL. Post-bulbar duodenal ulcers. Gastroenterology 1947; 8: $1-13$.

5 Ramsdell JA, Bartholomew LG, Cain RS, Davis GD. Postbulbar duodenal ulcer. Ann Intern Med 1957; 47: 700-10.

6 Kaufman SA, Levene G. Post-bulbar duodenal ulcer. Radiology 1957; 69: 848-52.

7 Dogra JR. Incidence of peptic ulcer in India with special reference to South India. Indian f Med Res 1941; 29: 665-76. Konstam PG. Peptic ulcer in India. Indian F Med Sci 1959; 13 486-92.

9 Malhotra SL. Epidemiological study of peptic ulcer in the south of India. Observations from Madras on the changing incidence of peptic ulcer with special reference to causation. Gut 1967; 8: 180-8.

10 Rao VG. A note on the problem of peptic ulcer in Hyderabad. Indian Council of Medical Research Report on Peptic Ulcer. No. 39. New Delhi: 1959: 16-26.

11 Madangopalan N, Balakumar K, Jaishreegajraj A. Epidemiology of peptic ulcer in India. Indian $\mathcal{F}$ Gastroenterol 1985; 5 : ology

12 Khuroo MS, Mahajan R, Zargar SA, Javid G, Munshi S Prevalence of peptic ulcer in India: an endoscopic and epidemiological study in urban Kashmir. Gut 1989; 30 $930-4$

13 Ogilvie $H$. The problem of peptic ulceration. Lancet 1953; i $555-60$.

14 Anonymous. Diet and peptic ulcer. [Editorial]. Lancet 1987; ii $80-1$

15 Malhotra SL. Peptic ulcer in India and its aetiology. Gut 1964; 5: 412-6.

16 Malhotra SL. Role of saliva in the aetiology of peptic ulcer. BMF 1965: 1: 1220-3.
17 Salmon BR, Brown P, Heut T, Read AE. Endoscopic examination of the duodenal bulb: clinical evaluation of forward and side viewing fiberoptic system in 200 cases. Gut 1972; 13: $170-5$

18 Dooley CP, Larson AW, Stace NH, Renner IG, Valenzuela $\mathrm{JE}$, Eliasoph J, et al. Double contrast barium meal and upper gastrointestinal endoscopy: A comparative study. Ann Intern Med 1984; 101: 538-45.

19 Gear MW, Wilkinson SP. Open access alimentary endoscopy. Br F Hosp Med 1989; 41: 438-44.

20 Mollmann KM, Bonnevie O, Gudbrand-Hoyer E, Wulff HR. A diagnostic study of patients with upper abdominal pain Scand 7 Gastroenterol 1975; 10: 805-9.

21 Friedman GD, Siegelaub AB, Seltzer CC. Cigarettes, alcohol, coffee, and peptic ulcer. N Engl ₹ Med 1974; 290: 469-73.

22 Dubey P,Sundaram KR, Nundy S. Effect of tea on gastric acid secretion. Dig Dis Sci 1984; 29: 202-6.

23 Malhotra SL. A comparison of unrefined wheat and rice diets in the management of duodenal ulcer. Postgrad Med $\mathcal{F} 1978$; 54: 6-9.

24 Myers BM, Smith JL, Graham DY. Effect of red and black pepper on the human stomach. Gastroenterology 1986; 90 A1561.

25 Desai HG, Karlo RH. Effect of black pepper and asafoetida on the DNA content of gastric aspirates. Indian 7 Med Res 1985; 8: 325-9.

26 Desai HG, Venugopalan K, Antia FP. Effect of red chilli powder on DNA content of gastric aspirates. Gut 1973; 14: 974-6.

27 Schneider MA, Deluca V Jr, Gray SJ. The effect of spices ingestion upon the stomach. Am $\mathcal{F}$ Gastroenterol 1956; 26 : ingestion

28 Macdonald WC, Anderson FH, Hashimoto S. Histological effect of certain pickles on the human gastric mucosa: a preliminary report. Can Med Ass $\mathcal{F}$ 1967; 96: 1521-5.

29 Kumar N, Vij JC, Sarin SK, Anand BS. Do chillies influence healing of duodenal ulcer. $B M \mathcal{F} 1984 ; 288$ : $1803-4$

30 Graham DY, Adam E, Reddy GT, Agarwal JP, Agarwal R Evans JD, et al. Seroepidemiology of Helicobacter pylori infection in India. Comparison of developing and developed countries. Dig Dis Sci 1991; 36: 1084-8.

31 Weisberg H, Jerzy Glass GB. Coexisting gastric and duodenal ulcers. A review. Am 7 Dig Dis 1963; 8: 992-1007.

32 Rumball JM. Coexistent duodenal ulcer. Gastroenterology 1971;61: 622-7.

33 Sun DCH, Stempun SJ. Site and size of ulcers as determinants of outcome. Gastroenterology 1971; 61: 576-84

34 Earlam R. A computerized questionnaire analysis of duodenal ulcer symptoms. Gastroenterology 1976; 71: 314-7.

35 Horrocks JC, DeDombal FT. Clinical presentation of patients with dyspepsia. Detailed symptomatic study of 360 patients. Gut 1978; 19: 19-26.

36 Rinaldo Jr JA,Scheinok P, Rupe CE. Symptom diagnosis. A mathematical analysis of epigastric pain. Ann Intern Med 1963; 59: 145-54.

37 Peterson H, Johannessen T, Kleveland P, Fjoone U, Dybdah $\mathrm{JH}$, Waldom HL. Do we need to listen to the patient? The predictive value of symptoms. Scand f Gastroenterol 1988; 23 (suppl 155): $30-4$. 